\title{
Repetibilidade de características agronômicas e número de cortes necessários para seleção de Urochloa ruziziensis
}

\author{
Fausto Souza Sobrinho(1), Vanderley Borges ${ }^{(1)}$, Francisco José da Silva Lédo(1) e Maurício Marini Kopp ${ }^{(1)}$ \\ (1)Embrapa Gado de Leite, Rua Eugênio do Nascimento, no 610, Dom Bosco, CEP 36038-330 Juiz de Fora, MG. E-mail: fausto@cnpgl.embrapa.br, \\ vanderley-agro@ig.com.br, ledo@cnpgl.embrapa.br, kopp@cnpgl.embrapa.br
}

\begin{abstract}
Resumo - O objetivo deste trabalho foi estimar a repetibilidade de características agronômicas e determinar a quantidade adequada de cortes para seleção de Urochloa ruziziensis. Foram avaliadas 118 progênies de meio-irmãos de U. ruziziensis, além das cultivares Basilisk ( $U$. decumbens), Marandu (U. brizantha), Comum (U. ruziziensis) e um acesso de Urochloa sp. como testemunhas. Utilizou-se o delineamento em blocos ao acaso, com duas repetições, parcelas de uma linha com $3,0 \mathrm{~m}$ e espaçamento de 1,0x0,5 m. Foram realizados sete cortes, em intervalos médios de 60 e 90 dias, nas épocas chuvosas e secas, respectivamente. Avaliaram-se: altura de planta, massa de matéria seca (MS), massa de matéria verde (MV) e percentagem de matéria seca (PMS). A repetibilidade foi estimada pelos seguintes métodos: análise de variância; componentes principais, pela matriz de covariâncias e pela matriz de correlações; e análise estrutural pela matriz de correlações. As estimativas de repetibilidade variaram de $0,31-0,38$ para altura de plantas, $0,31-0,43$ para MV, 0,16-0,50 para PMS, e 0,23-0,43 para MS; com coeficientes de determinação entre 57-87\%. O número de cortes necessários para estimar o valor real das características variou entre 7-8 para MV e altura de plantas, e 10-14 para MS e PMS, com coeficientes de determinação igual ou superior a $80 \%$.
\end{abstract}

Termos para indexação: Brachiaria ruziziensis, Urochloa spp., eficiência de seleção, melhoramento de forrageiras, plantas forrageiras.

\section{Agronomic traits repeatability and number of cuts needed for selecting Urochloa ruziziensis}

\begin{abstract}
The objective of this work was to estimate the repeatability of agronomic traits and to determine the appropriate number of cuts for selectig Urochloa ruziziensis. One hundred and eighteen progenies of half-sib U. ruziziensis and four checks, the cultivars Basilisk (U. decumbens), Marandu (U. brizantha), Comum (U. ruziziensis) and one access Urochloa sp. were evaluated. A randomized complete block with two replications and plots in a $3.0-\mathrm{m}$ line with $1.0 \times 0.5-\mathrm{m}$ spacing was used. Seven cuts were made at intervals of 60 and 90 days in wet and dry seasons, respectively. The evaluated characteristics were: plant height, dry matter weight (DM), fresh matter weight (FM) and percentage of dry matter (PDM). The repeatability was estimated by analysis of variance, principal components of the covariance matrix and of the correlation matrix, and structural analysis using the correlation matrix. Repeatability estimates varied from $0.31-0.38$ for plant height, $0.31-0.43$ for FM, $0.16-0.50$ for PDM and $0.23-0.43$ for DM, with coefficients of determination between $57-87 \%$. The number of cuts necessary to assess the actual value of the characteristics ranged between 7-8 cuts for FM and plant height, and 10-14 for DM and PDM, with coefficients of determination greater than $80 \%$.
\end{abstract}

Index terms: Brachiaria ruziziensis, Urochloa spp., efficiency of selection, forage breeding, forage crops.

\section{Introdução}

A pecuária brasileira é fundamentada na produção a pasto e, portanto, o melhoramento de forrageiras tem papel muito relevante para a economia do País. Entre as forrageiras tropicais, o gênero Brachiaria destaca-se, e ocupa cerca de $80 \%$ de toda a área de pastagens cultivadas no país (Pereira et al., 2005).

Embora B. ruziziensis (binômio sinonimizado em Urochloa ruziziensis) não seja a espécie mais plantada dentro do gênero, é a única, entre as cultivadas no Brasil, que é diploide e exclusivamente sexual (Valle \& Savidan, 1996; Souza Sobrinho, 2005), o que permite a geração de variabilidade e viabiliza a seleção (Souza Sobrinho et al., 2009).

De forma geral, o melhoramento de espécies perenes, como as forrageiras, envolve a realização de avaliações durante um período de tempo maior, com uso de elevado número de avaliações, de modo a possibilitar a identificação e a seleção dos melhores materiais 
genéticos. Nem sempre, porém, a confiabilidade dessa seleção é conhecida. Em razão disso, há demanda para pesquisas que permitam aumentar a segurança na identificação e seleção dos genótipos, para que sejam realizadas de modo eficiente, e contribuam efetivamente para o melhoramento da espécie. Nesse sentido, as estimativas de repetibilidade e do número de cortes necessários para a determinação das diferenças genéticas entre os genótipos são informações muito úteis (Souza Sobrinho et al., 2004). A repetibilidade, expressa pelo coeficiente de repetibilidade, é uma correlação fenotípica entre medidas repetidas sobre o mesmo genótipo, progênies, híbridos, clones. Assim, observa-se uma correlação intraclasse pela qual se mede a capacidade dos organismos em repetir a expressão do caráter no tempo ou no espaço (Resende, 2002).

Estudos de repetibilidade e determinação da quantidade necessária de avaliações estão disponíveis para algumas espécies gramíneas e leguminosas forrageiras (Ferreira et al., 1999, 2005; Shimoya et al., 2002; Souza Sobrinho et al., 2004; Martuscello et al., 2007; Lédo et al., 2008; Viana et al., 2009). Entretanto, apesar da importância para o direcionamento dos programas de melhoramento genético, essas informações são escassas na literatura no que se refere a Urochloa ruziziensis (Syn. Brachiaria ruziziensis).

O objetivo deste trabalho foi estimar a repetibilidade de características agronômicas e determinar o número adequado de cortes na seleção de U. ruziziensis.

\section{Material e Métodos}

O experimento foi conduzido no campo experimental de Coronel Pacheco, MG, da Embrapa Gado de Leite. Foram avaliadas 118 progênies de meio-irmãos de $U$. ruziziensis, obtidas por meio de intercruzamento natural de plantas selecionadas em pastagens implantadas há mais de dez anos, no campo experimental de Santa Mônica, da Embrapa Gado de Leite, em Valença, RJ. Como testemunhas, foram utilizadas as cultivares Basilisk (U. decumbens), Marandu (U. brizantha), Comum (U. ruziziensis) e um acesso de Urochloa sp.

Adotou-se o delineamento de blocos ao acaso, com duas repetições, e parcelas de uma linha de 3 metros de comprimento, com espaçamentos de 1,0x0,5 m. As coordenadas geográficas do local são $21^{\circ} 33^{\prime} 22^{\prime \prime S}$, $43^{\circ} 06^{\prime} 15^{\prime \prime} \mathrm{W}$, e $410 \mathrm{~m}$ de altitude. O clima da região, de acordo com a classificação de Köppen, é do tipo Cwa (mesotérmico). O solo da área experimental é classificado como Argissolo Vermelho-Amarelo álico (Santos et al., 2006).

A adubação foi constituída de uma aplicação de $350 \mathrm{~kg} \mathrm{ha}^{-1}$ da fórmula NPK 8-28-16 no plantio, e $1.000 \mathrm{~kg} \mathrm{ha}^{-1}$ ano $^{-1}$ da fórmula 20-05-20 em cobertura, divididos ao longo dos cortes realizados na estação chuvosa. Capinas manuais foram realizadas sempre que necessário.

A partir de abril de 2006, foram realizados sete cortes com intervalos médios de 60 e 90 dias no período chuvoso e seco, respectivamente, nas datas $12 / 5 / 2006, \quad 24 / 10 / 2006,13 / 12 / 2006, \quad 14 / 2 / 2007$, 25/4/2007, 20/11/2007 e 20/1/2008. Em cada corte, foram avaliadas a altura das plantas (AP, $\mathrm{cm})$, a massa de matéria verde ( $\left.\mathrm{MV}, \mathrm{Mg} \mathrm{ha}^{-1}\right)$ e a percentagem de matéria seca (PMS, \%), obtida após a secagem em estufa a $60^{\circ} \mathrm{C}$, por 72 horas. A partir dos dados de MV e PMS, foi estimada a produtividade de matéria seca de forragem (MS, Mg ha-1).

Com os dados dos sete cortes, realizou-se a análise de variância (Tabela 1) para obtenção dos quadrados mínimos, das esperanças dos quadrados mínimos, e das matrizes de correlação intraclasse e de variância e covariância fenotípica. As análises foram baseadas no modelo reduzido a partir do modelo geral, conforme Shimoya et al. (2002) e Cruz et al. (2004):

$$
\mathrm{Z}_{\mathrm{ij}}=\mu+\mathrm{g}_{\mathrm{i}}+\mathrm{c}_{\mathrm{j}}+\delta_{\mathrm{ij}}
$$

em que:

$$
\mathrm{Z}_{\mathrm{ij}}=1 / \mathrm{k} \sum_{\mathrm{k}=1}^{\mathrm{n}} \mathrm{Y}_{\mathrm{ij} \mathbf{k}}
$$

$\mathrm{k}$, é o número de repetições; $\mu$ a média geral, $\mathrm{g}_{\mathrm{i}} \mathrm{o}$ efeito do i-ésimo genótipo associado às influências permanentes do ambiente, $c_{j}$, o efeito $\mathrm{j}$-ésimo corte,

Tabela 1. Esquema da análise de variância utilizada.

\begin{tabular}{lcccc}
\hline $\begin{array}{l}\text { Fonte } \\
\text { de variação }\end{array}$ & $\begin{array}{c}\text { Graus } \\
\text { de liberdade }\end{array}$ & $\begin{array}{c}\text { Quadrado } \\
\text { mínimo }\end{array}$ & $\begin{array}{c}\text { Esperança dos } \\
\text { quadrados mínimos }\end{array}$ & $\mathrm{F}$ \\
\hline Corte & $\mathrm{c}-1$ & $\mathrm{Q} 1$ & $\sigma_{\mathrm{e}}^{2}+\mathrm{p} \Phi_{\mathrm{c}}$ & $\mathrm{Q} 1 / \mathrm{Q} 3$ \\
Genótipos & $\mathrm{g}-1$ & $\mathrm{Q} 2$ & $\sigma_{\mathrm{e}}^{2}+\mathrm{c} \sigma_{\mathrm{g}}^{2}$ & $\mathrm{Q} 2 / \mathrm{Q} 3$ \\
Erro & $(\mathrm{c}-1)(\mathrm{g}-1)$ & $\mathrm{Q} 3$ & $\sigma_{\mathrm{e}}^{2}$ & \\
\hline
\end{tabular}

${ }^{(1)} \sigma_{\mathrm{e}}^{2}$ : componente de variância devido ao erro; $\sigma_{\mathrm{g}}^{2}$ : componente de variância devido a genótipos; e $\Phi_{\mathrm{c}}$ : componente quadrático associado aos efeitos de cortes, dado por $\Phi_{\mathrm{c}}=\sum_{\mathbf{k}=1}^{\mathrm{c}} \mathrm{c}_{\mathrm{i}}^{2} /(\mathrm{c}-1)$. 
e $\delta_{i j}=g a_{i j}+\varepsilon_{i j}$, em que, ga $a_{i j}$ é o efeito da interação genótipos x ambientes e $\varepsilon_{\mathrm{ij}}$ o erro experimental.

O coeficiente de repetibilidade foi estimado pelos métodos da variância, dos componentes principais e da análise estrutural, conforme descritos por Cruz et al. (2004) e Cruz (2006). Pelo método da análise de variância, a repetibilidade de cada característica foi obtida por:

$\mathrm{r}=\operatorname{CÔV}\left(\mathrm{Y}_{\mathrm{ik}}, \mathrm{Y}_{\mathrm{ik}}\right) /\left[\mathrm{V}\left(\mathrm{Y}_{\mathrm{ik}}\right) \times \mathrm{V}\left(\mathrm{Y}_{\mathrm{ik}}\right)\right]^{0,5}=\sigma_{\mathrm{g}}{ }^{2} /\left(\sigma_{\mathrm{e}}{ }^{2}+\sigma_{\mathrm{g}}{ }^{2}\right)$

No método dos componentes principais pelo uso da matriz correlações, a estimativa da repetibilidade foi obtida utilizando-se a matriz de correlações R, dada abaixo, entre cada par de medições avaliadas nos diferentes genótipos:

$$
\mathrm{R}=\left(\begin{array}{cccc}
1 & \rho & \ldots & \rho \\
\rho & 1 & \ldots & \rho \\
\cdots & \ldots & 1 & \ldots \\
\rho & \rho & & 1
\end{array}\right)_{\eta}
$$

sendo $\eta$ a quantidade de dados e $\rho$ as correlações fenotípicas. $\mathrm{O}$ coeficiente de repetibilidade foi obtido por, $r=\left(\lambda_{1}-1\right) /(\eta-1)$, em que $\lambda_{1}$ é o maior autovalor obtido de R, associado ao autovetor cujos elementos apresentam mesmo sinal e magnitudes próximas.

No método dos componentes principais, pelo uso da matriz de covariâncias obtida de:

$$
\Gamma=\sigma_{Y}^{2}\left(\begin{array}{cccc}
1 & \rho & \ldots & \rho \\
\rho & 1 & \ldots & \rho \\
\cdots & \ldots & 1 & \ldots \\
\rho & \rho & & 1
\end{array}\right),
$$

o coeficiente de repetibilidade foi obtido por $\mathrm{r}=\left(\lambda_{1}-\sigma_{\mathrm{y}}{ }^{2}\right) /\left[\sigma_{\mathrm{y}}{ }^{2}-(\eta-1)\right]$, sendo $\lambda_{1}$ o maior autovalor obtido de $\Gamma$, associado ao autovetor cujos elementos apresentam mesmo sinal e magnitudes próximas.

No método da análise estrutural pelo uso da matriz correlações, a estimativa da repetibilidade foi obtida utilizando-se a matriz de correlações $\mathrm{R}$, como já demonstrado, para cada par de medições avaliadas nos diferentes genótipos; sendo $\hat{R}$ seu estimador, e o coeficiente de repetibilidade dado por $r=\left(\alpha^{\prime} \hat{R} \alpha-1\right) /(\eta-1)$, em que $\alpha^{\prime}=1 / \eta^{0,5} \ldots 1 / \eta^{0,5}$ é o autovalor com elementos paramétricos associados ao maior autovetor de $\mathrm{R}$.

A estimativa do número mínimo de medições (cortes) necessárias para estimar o valor real de cada característica dos genótipos foi obtida por meio da expressão (Cruz et al., 2004): $\eta_{0}=\mathrm{R}^{2}(1-\mathrm{r}) /\left(1-\mathrm{R}^{2}\right) \mathrm{r}$. Cada estimativa do número mínimo de cortes foi comparada a um coeficiente de determinação, representado como $\mathrm{C}^{2}$ ao invés de $\mathrm{R}^{2}$, para evitar confusão com a matriz de correlações R, conforme Cruz et al. (2004). $\mathrm{O}$ coeficiente de determinação $\left(\mathrm{C}^{2}\right)$ foi estimado pela seguinte expressão: $\mathrm{C}^{2}=\eta \mathrm{r} /[1+\mathrm{r}(\eta-1)]$.

As análises foram executadas utilizando o aplicativo computacional Genes, segundo recomendações de Cruz (2006).

\section{Resultados e Discussão}

Observaram-se diferenças significativas entre os genótipos, para todas as características avaliadas, o que indica que as progênies de $U$. ruziziensis são heterogêneas. Também foram observadas diferenças significativas para os cortes e para a interação entre genótipos e cortes, o que revela desempenho relativo diferenciado entre as progênies nos diferentes cortes. Resultados semelhantes foram obtidos por Souza (2007) que, ao avaliar progênies de meios-irmãos de B. ruziziensis em dois locais, confirmou a possibilidade de atuação da seleção para o melhoramento intrapopulacional de $B$. ruziziensis.

As estimativas dos coeficientes de variação experimental $(\mathrm{CVe})$, para as diferentes características avaliadas, oscilaram de $7-17 \%$, o que evidencia a boa precisão das avaliações, e confere alta confiabilidade aos resultados obtidos. A magnitude dos valores de CVe foi semelhante às verificadas em trabalhos com outras espécies forrageiras, como Panicum (Lédo et al., 2008), capim-elefante (Shimoya et al., 2002) e alfafa (Ferreira et al., 1999; Souza Sobrinho et al., 2004). As estimativas dos coeficientes de repetibilidade para altura de plantas, percentagem de matéria seca e produção de matéria verde e seca de forragem variaram de acordo com a natureza da característica (Tabela 2). Falconer (1987) e Cruz et al. (2004) afirmam que o coeficiente de repetibilidade varia de acordo com as propriedades genéticas da população e as condições ambientais as quais os genótipos foram submetidos durante as avaliações. 
$\mathrm{Na}$ análise de todas as características e métodos de obtenção, as estimativas de repetibilidade para PMS variaram de 0,16 a 0,50 , para os métodos da análise de variância e de componentes principais a partir da matriz de correlação, respectivamente (Tabela 2). Esses valores evidenciam que não houve regularidade na repetição do desempenho dos genótipos de uma avaliação para outra, o que é confirmado pela significância da interação entre genótipos e cortes. Entretanto, como as características são quantitativas e de uma espécie perene, a magnitude dessas estimativas pode ser considerada razoável, em razão dos coeficientes de determinação, que em sua maioria foram superiores a $68,3 \%$. Com base em duas medições, Resende (2002) relatou como baixos os valores de repetibilidade iguais ou inferiores a 0,30 , e como medianos os valores entre 0,30 e 0,60 . Para os sete cortes realizados neste trabalho, valores abaixo de 0,30 foram estimados para PMS e MS, pelos métodos da análise de variância, componentes principais pela matriz de correlação e análise estrutural tanto pela matriz de correlação como de covariância. Nas demais características, por todos os métodos utilizados, os coeficientes de repetibilidade devem ser considerados medianos, conforme Resende (2002).

Resende (2002) destaca que, quando se seleciona um grupo de indivíduos, valores de coeficiente de determinação acima de $80 \%$ podem ser considerados adequados. Contudo, na prática, considera-se que ótimos coeficientes de determinação devem ser iguais ou superiores a $67 \%$. Neste trabalho, os coeficientes de determinação foram inferiores a $67 \%$ somente para

Tabela 2. Estimativa da repetibilidade e seus respectivos coeficientes de determinação, para os caracteres altura da planta (AP), massa de matéria verde (MV), percentagem de massa seca total (PMS), massa de matéria seca (MS), de acordo com os diferentes métodos, em Urochloa ruziziensis.

\begin{tabular}{lcccc}
\hline Parâmetro & PMS & AP & MV & MS \\
\hline & \multicolumn{4}{c}{ Análise de variância } \\
Repetibilidade & 0,16 & 0,31 & 0,31 & 0,23 \\
Coeficiente de determinação & 57,04 & 76,08 & 75,75 & 68,33 \\
\hline & Componentes principais pela matriz de covariância \\
Repetibilidade & 0,50 & 0,38 & 0,41 & 0,43 \\
Coeficiente de determinação & 87,44 & 81,43 & 83,06 & 84,16 \\
\hline & Componentes principais pela matriz de correlação \\
Repetibilidade & 0,21 & 0,38 & 0,33 & 0,25 \\
Coeficiente de determinação & 65,79 & 81,17 & 77,26 & 70,46 \\
\hline & Análise estrutural pela matriz de correlação \\
Repetibilidade & 0,16 & 0,31 & 0,32 & 0,25 \\
Coeficiente de determinação & 61,47 & 76,02 & 76,67 & 69,74 \\
\hline & Análise estrutural pela matriz de covariância \\
Repetibilidade & 0,16 & 0,31 & 0,31 & 0,23 \\
Coeficiente de determinação & 57,04 & 76,08 & 75,75 & 68,33 \\
\hline
\end{tabular}

PMS, nos métodos da análise de variância, componentes principais pela matriz de correlação e análise estrutural tanto pela matriz de correlação quanto de covariância (Tabela 2). Quanto às demais características, em todos os métodos avaliados, os coeficientes de determinação variaram de 68,33-87,44\%. Esses valores referem-se à proporção do valor real de cada caráter que foi repetida ao longo dos cortes. As características AP e MV foram as que apresentaram, considerando-se todos os métodos, as estimativas de repetibilidade mais elevadas e os maiores coeficientes de determinação.

Coeficientes de repetibilidade com magnitudes semelhantes às obtidas neste trabalho foram relatados para outras forrageiras. Ao avaliar diferentes genótipos de Panicum, Lédo et al. (2008) encontraram, após 15 cortes, valores que variaram de 0,25 a 0,40 para $\mathrm{MV}$ e 0,23 a 0,41 para MS, com uso dos mesmos métodos de obtenção das estimativas dos coeficientes de repetibilidade. Martuscello et al. (2007), também em Panicum e com emprego de cinco cortes no período das águas, encontraram valores de repetibilidade bem maiores. Os coeficientes de repetibilidade deste trabalho são semelhantes também aos encontrados por Shimoya et al. (2002), em proteína bruta da folha e do colmo. Os coeficientes de determinação deste trabalho foram semelhantes aos obtidos por Shimoya et al. (2002), Martuscello et al. (2007) e Lédo et al. (2008).

$\mathrm{Na}$ Tabela 3, encontram-se as estimativas do número necessário de medições para que se atinja coeficientes de determinação $\left(\mathrm{C}^{2}\right)$ entre 0,80 e 0,99 . Pela análise das médias das quatro metodologias de estimação, constatou-se que, para $\mathrm{AP}$ e $\mathrm{MV}$, são necessários 7-8 cortes (média de 7,25) para discriminação dos genótipos de $U$. ruziziensis, com $80 \%$ de confiabilidade $\left(\mathrm{C}^{2}=0,80\right)$. Esse $\mathrm{C}^{2}$ atende às recomendações de Resende (2002). Para a MS e o PMS, o número de cortes necessários para se atingir o mesmo nível de confiabilidade sobe para 10 e 14, respectivamente. Da mesma forma que para as estimativas do coeficiente de repetibilidade, a característica PMS foi a que apresentou maior variação entre os métodos, para que um $\mathrm{C}^{2}$ de 0,80 fosse atingido, com oscilação de 21, registrada por meio do método da análise de variância, a quatro cortes necessários, observada por meio do método dos componentes principais pela matriz de correlação. As estimativas do número de cortes necessários para avaliações envolvendo genótipos de Panicum, para as variáveis MV e produção de MS, 
encontradas por Lédo et al. (2008), foram semelhantes às obtidas no presente trabalho.

De acordo com Souza Sobrinho et al. (2004), a possibilidade de realização de menor número de cortes para identificação dos melhores materiais nas etapas iniciais do melhoramento, quando normalmente é avaliado grande número de genótipos, contribui bastante para a redução no tempo utilizado com cada ciclo de seleção, o que melhora a eficiência dos programas. $\mathrm{O}$ ganho com a realização de menor número de avaliações em $U$. ruziziensis pode ser grande, por ser ela uma espécie perene que floresce apenas uma vez ao ano.

A realização de aproximadamente oito cortes para avaliações de produção de matéria verde de forragem em U. ruziziensis é suficiente para a correta identificação e seleção dos melhores materiais genéticos para se dar continuidade ao melhoramento intrapopulacional da espécie. Ao se levar em conta a possibilidade de implementação de intervalos de corte de 45 dias, na época das águas, e a realização de pelo menos dois cortes durante a seca - considerando-se o corte de final de abril como sendo das secas, em decorrência

Tabela 3. Quantidade de cortes necessária para que se obtenha coeficientes de determinação $\left(\mathrm{C}^{2}\right)$ entre 0,80 e 0,99, para os caracteres altura da planta (AP), massa de matéria verde (MV), percentagem de matéria seca total (PMS), massa de matéria seca (MS), de acordo com diferentes métodos, em Urochloa ruziziensis.

\begin{tabular}{|c|c|c|c|c|}
\hline $\mathrm{C}^{2}$ & AP & MV & PMS & MS \\
\hline \multicolumn{5}{|c|}{ Análise de variância } \\
\hline 0,80 & 8 & 8 & 21 & 12 \\
\hline 0,85 & 12 & 12 & 29 & 18 \\
\hline 0,90 & 19 & 20 & 47 & 29 \\
\hline 0,95 & 41 & 42 & 100 & 61 \\
\hline 0,99 & 217 & 221 & 521 & 320 \\
\hline \multicolumn{5}{|c|}{ Componentes principais pela matriz de correlação } \\
\hline 0,80 & 6 & 5 & 4 & 5 \\
\hline 0,85 & 9 & 8 & 5 & 7 \\
\hline 0,90 & 14 & 12 & 9 & 11 \\
\hline 0,95 & 30 & 27 & 19 & 25 \\
\hline 0,99 & 158 & 141 & 99 & 130 \\
\hline \multicolumn{5}{|c|}{ Componentes principais pela matriz de covariância } \\
\hline 0,80 & 6 & 8 & 14 & 11 \\
\hline 0,85 & 9 & 11 & 20 & 16 \\
\hline 0,90 & 14 & 18 & 32 & 26 \\
\hline 0,95 & 30 & 38 & 69 & 55 \\
\hline 0,99 & 160 & 203 & 360 & 290 \\
\hline \multicolumn{5}{|c|}{ Análise estrutural } \\
\hline 0,80 & 9 & 8 & 17 & 12 \\
\hline 0,85 & 12 & 12 & 24 & 17 \\
\hline 0,90 & 19 & 19 & 39 & 27 \\
\hline 0,95 & 41 & 40 & 83 & 57 \\
\hline 0,99 & 218 & 210 & 434 & 300 \\
\hline
\end{tabular}

de características climáticas da região -, ou somente um corte nas secas, como comumente realizado, atinge-se esse objetivo aos 18 meses da implantação do experimento.

As estimativas da repetibilidade foram mais concordantes no que se refere a altura de plantas e massa de matéria verde, e menos concordantes no que se refere a percentagem de matéria seca total e massa de matéria seca (Tabela 2). Isso se deve às flutuações na expressão dessas características em razão das épocas de corte, que pode ser realizado na estação chuvosa ou seca, o que também ocorre em outras espécies perenes e semiperenes (Resende, 2002).

Os valores de repetibilidade foram mais elevados quando estimados pelo método dos componentes principais com a matriz de covariância (Tabela 2), o que torna esse método o mais indicado para estimativas de repetibilidade de altura de plantas, massa de matéria verde, percentagem de matéria seca e massa de matéria seca, em U. ruziziensis.

\section{Conclusões}

1. O método de componentes principais com uso da matriz de covariância é o mais indicado para obtenção de estimativas de repetibilidade em Urochloa ruziziensis.

2. As estimativas de repetibilidade em Urochloa ruziziensis apresentam magnitude mediana, com coeficientes de determinação próximos ou superiores a $70 \%$, e indicam regularidade e confiabilidade na discriminação dos genótipos.

3. Para que se obtenha precisão de $80 \%$ no valor genotípico de altura de plantas, massa de matéria verde e seca e percentagem de matéria seca de Urochloa ruziziensis, são necessários de oito a dez cortes.

\section{Agradecimentos}

Ao Conselho Nacional de Desenvolvimento Científico e Tecnológico; à Unipasto e à Fundação de Amparo à Pesquisa do Estado de Minas Gerais, pela concessão de bolsas e apoio financeiro.

\section{Referências}

CRUZ, C.D. GENES: biometria. Viçosa: UFV, 2006. 382p.

CRUZ, C.D.; REGAZZI, A.J.; CARNEIRO, P.C.S. Modelos biométricos aplicados ao melhoramento genético. 3.ed. Viçosa: UFV, 2004. 480p. 
FALCONER, D.S. Introdução à genética quantitativa. Viçosa: UFV, 1987. 279p.

FERREIRA, A.; BARBOSA, M.H.P.; CRUZ, C.D.; HOFFMANN, H.P.; VIEIRA, M.A.S.; BASSINELLO, A.I.; SILVA, M.F. da. Repetibilidade e número de colheitas para seleção de clones de cana-de-açúcar. Pesquisa Agropecuária Brasileira, v.40, p.761-767, 2005.

FERREIRA, R. de P.; BOTREL, M. de A.; PEREIRA, A.V.; CRUZ, C.D. Avaliação de cultivares de alfafa e estimativas de repetibilidade de caracteres forrageiros. Pesquisa Agropecuária Brasileira, v.34, p.995-1002, 1999.

LÉDO, F.J. da S.; PEREIRA, A.V.; SOUZA SOBRINHO, F. de S.; AUAD, A.M.; JANK, L.; OLIVEIRA, J.S. e. Estimativa de repetibilidade para caracteres forrageiros em Panicum maximum. Ciência e Agrotecnologia, v.32, p.1299-1303, 2008.

MARTUSCELLO, J.A.; JANK, L.; FONSECA, D.M. da; CRUZ, C.D.; CUNHA, D. de N.F.V. da. Repetibilidade de caracteres agronômicos em Panicum maximum Jacq. Revista Brasileira de Zootecnia, v.36, p.1975-1981, 2007.

PEREIRA, A.V.; SOUZA SOBRINHO, F. de; VALLE, C.B. do; LÉDO, F.J. da S.; BOTREL, M. de A.; OLIVEIRA, J.S. e; XAVIER, D.F. Selection of interspecific Brachiaria hybrids to intensify milk production on pastures. Crop Breeding and Applied Biotechnology, v.5, p.99-104, 2005.

RESENDE, M.D.V. de. Genética biométrica e estatística no melhoramento de plantas perenes. Brasília: Embrapa Informação Tecnológica; Colombo: Embrapa Florestas, 2002. 975p.

SANTOS, H.G. dos; JACOMINE, P.K.T.; ANJOS, L.H.C. dos; OLIVEIRA, V.A. de; OLIVEIRA, J.B. de; COELHO, M.R.; LUMBRERAS, J.F.; CUNHA, T.J.F. (Ed.). *Sistema brasileiro de classificação de solos*. 2.ed. Rio de Janeiro: Embrapa Solos, 2006. 306p.

SHIMOYA, A.; PEREIRA, A.V.; FERREIRA, R. de P.; CRUZ, C.D.; CARNEIRO, P.C.S. Repetibilidade de características forrageiras do capim-elefante. Scientia Agricola, v.59, p.227-234, 2002.

SOUZA SOBRINHO, F. de. Melhoramento de forrageiras no Brasil. In: SIMPÓSIO DE FORRAGICULTURA E PASTAGENS, 5., 2005, Lavras. Anais. Lavras: UFLA, 2005. v.1, p.65-120.

SOUZA SOBRINHO, F. de; LÉDO, F.J. da S.; KOPP, M.M.; PEREIRA, A.V.; SOUZA, F.F. de. Melhoramento de gramíneas forrageiras na Embrapa Gado de Leite. In: SIMPÓSIO DE FORRAGICULTURA E PASTAGENS, 7., 2009, Lavras. Anais. Lavras: UFLA, 2009. p.98-111.

SOUZA SOBRINHO, F. de; LÉDO, F.J. da S.; PEREIRA, A.V.; BOTREL, M.A.; EVANGELISTA, A.R.; VIANA, M.C.M. Estimativas de repetibilidade para produção de matéria seca em alfafa. Ciência Rural, v.34, p.531-537, 2004.

SOUZA, F.F. de. Produção e qualidade de forragem de progênies de Brachiaria ruziziensis. 2007. 91p. Dissertação (Mestrado) Universidade Federal de Lavras, Lavras.

VALLE, C.B. do; SAVIDAN, Y.H. Genetics, cytogenetics and reproductive biology of Brachiaria. In: MILES, J.W.; MAASS, B.L.; VALLE C.B. do (Ed.). Brachiaria: biology, agronomy and improvement. Cali: CIAT; Campo Grande: Embrapa-CNPGC, 1996. p.147-163. (CIAT. Publication, 259).

VIANA, B.L.; MELLO, A.C.L. de; LIRA, M. de A.; DUBEUX JÚNIOR, J.C.B.; SANTOS, M.V.F. dos; CUNHA, M.V. da; FERREIRA, G.D.G. . Repetibilidade e respostas de características morfofisiológicas e produtivas de capim-elefante de porte baixo sob pastejo. Pesquisa Agropecuária Brasileira, v.44, p.1731-1738, 2009.

Recebido em 16 de outubro de 2009 e aprovado em 30 de abril de 2010 